that current smoking rather than former smoking is most important in risk assessment for SLE development. ${ }^{15}$

\section{Cigarette smoking and the risk of systemic lupus erythematosus and rheumatoid arthritis}

\section{S Majka, V M Holers}

\section{Smoking may affect the disease course in SLE and patients should be counselled to stop}

r n this issue of the Annals, Freemer et al report an association between smoking and dsDNA autoantibody production in systemic lupus erythematosus (SLE). ${ }^{1}$ The authors note that exposure to tobacco smoke has previously been associated with several autoimmune diseases, including rheumatoid arthritis (RA) and SLE. In RA, cigarette smoking has been associated with rheumatoid factor (RF) positive but not RF negative disease when these two groups of subjects were evaluated separately. ${ }^{2-4}$ Likewise, smoking has been associated with anti-cyclic citrullinated antibody (anti-CCP) positive but not anti-CCP negative RA. ${ }^{5}$ In affected subjects, exposure to tobacco has also been associated with several measures of disease severity such as the presence of radiographic erosions, nodules, pulmonary disease, $\mathrm{RF}$, and anti-CCP antibodies. ${ }^{5-8} \mathrm{~A}$ cumulative dose of exposure has been associated with a higher incidence and prevalence of RA as well as RF and anti-CCP positivity ${ }^{5-9}$; in studies evaluating intensity and duration separately, it appears that duration is most important. ${ }^{310}$ Smoking has been identified as a risk factor for seropositive RA incidence, ${ }^{24}$ and a few studies have even identified an association between cigarette smoking and RF positivity in subjects without $\mathrm{RA}^{11-13}$ supporting a role for this exposure very early during the development of clinical disease. In this regard, it has been proposed that exposure to tobacco may trigger RF production, thus contributing to the clinical onset of RA. ${ }^{14}$

\section{SLE DEVELOPMENT AND CIGARETTE SMOKING}

While tobacco exposure has been causally linked to RA, the relationship between the development of SLE and cigarette smoking is less clear. A recent meta-analysis identified a modest association between the development of SLE and current, but not former smoking (odds ratio $(\mathrm{OR})=1.50,95 \%$ confidence interval (CI) 1.09 to 2.08$).{ }^{15}$ One limitation of that analysis is that the majority of the studies included did not have statistically significant associations and one outlying study had a high point estimate for the relationship $(\mathrm{OR}=6.7)$ in a predominately Hispanic population. ${ }^{16}$ Furthermore, in two studies examining the relationship between smoking and incident SLE, statistically significant associations were not identified. ${ }^{17}{ }^{18}$ Nevertheless, the previous identification in affected subjects of associations between smoking and severity of SLE may indicate that a relationship exists between smoking and SLE once clinical disease is established. For example, Ward and Studenski identified an association between SLE and progression of lupus nephritis to end stage renal disease. $^{19}$ Additionally, smokers were found to have significantly higher Systemic Lupus Erythematosus Disease Activity Index (SLEDAI) scores and a higher odds of thrombotic events..$^{21}$

As in the analysis of RA related autoantibodies, studies examining the association between tobacco exposure and presence of autoantibodies in clinically unaffected subjects are limited One previous study found an increased prevalence of antinuclear antibodies population cohort, ${ }^{12}$ while a recent small study found a negative correlation between smoking and IgG anti-DNA antibodies in subjects with SLE. ${ }^{22}$

With this background, the investigations undertaken by Freemer et al were warranted and their findings are a useful addition to this area of investigation. They found that current versus never smoking is associated with the presence of autoantibodies to double stranded DNA (dsDNA) (OR $=4.0,95 \%$ CI 1.6 to 10.4) as was current versus former smoking (OR $=3.0,95 \%$ CI 1.3 to 7.1). The OR for the association of ever smoking with dsDNA positivity was 1.5, and they found no relationship between dsDNA status and the duration of smoking in former smokers. These results are consistent with the metaanalysis of Costenbader et al showing (ANA) in smokers from a general
"Current smoking rather than former smoking is a greater risk factor for development of SLE"

Potential pitfalls of this study are relatively few and are mainly due to the inherent limitations of a case-control study. For example, smoking classification at the time of dsDNA testing may not be accurate given that it was collected by chart review. In the ideal setting, serum or urinary cotinine levels would provide a more accurate estimate of subjects' smoking status. Additionally, the magnitude of the association between smoking and dsDNA may have been attenuated by drug treatment for SLE, given that dsDNA is a marker of disease activity in SLE. In addition, the sample size limited the authors' ability to assess the relationship in different racial and ethnic groups. Such an assessment might be useful given that the point estimate for the association between tobacco and dsDNA was quite high $(\mathrm{OR}=6.7)$ in a predominately Hispanic cohort. ${ }^{16}$ Finally, as with any study evaluating SLE development and severity, as well as cigarette exposure, adjustment for socioeconomic status is also important.

\section{POSSIBLE MECHANISMS FOR ASSOCIATION BETWEEN CIGARETTE SMOKING, SLE, AND} RA

What is the mechanism for the identified associations between cigarette smoking and autoimmune connective tissue diseases? The molecular mechanisms causing the association between smoking, RA, and severity in RA have not been determined. However, several plausible hypotheses have been presented. Genetic susceptibility certainly may have a role, with the recent determination that a null polymorphism in the glutathione $S$-transferase (GST) Ml locus affects the association between RF and smoking in subjects with RA. ${ }^{23}$ The GST enzymes are believed to play an important part in detoxifying reactive oxygen species and, therefore, might influence the ability to detoxify chemicals in cigarette smoke. Additionally, another gene-environment interaction has been proposed, in which smoking might cause a modification of potential autoantigens being recognised by $\mathrm{T}$ cells that are restricted by major histocompatibility complex (MHC) antigens carrying the shared epitope. ${ }^{45}$ The authors suggest that smoking induces peptide deimination which leads to 
anti-CCP positive RA in subjects who carry the shared epitope. ${ }^{5}$ In addition, it has been shown that smoking increases Fas expression in B lymphocytes and CD4+ T lymphocytes. ${ }^{24}$ Thus, smoking might lead to increased apoptosis, causing exposure to intracellular citrullinated antigens with eventual breakdown of tolerance and induction of RA related autoimmunity, such as anti-CCP and RF production.

For SLE, one very well supported current hypothesis about the nature of pathogenic mechanisms in the disease proposes that ineffective clearance of apoptotic cells due to genetic or acquired deficiencies promotes the loss of self tolerance to nuclear antigens and subsequent $\mathrm{B}$ and $\mathrm{T}$ cell reactivity. ${ }^{25}$ Given that cigarette smoke is associated with an influx of short lived apoptosis-prone neutrophils into the lung as well as a decreased ability to clear these cells through phagocytosis by macrophages, ${ }^{26}$ the generation of anti-dsDNA may be indirect and related to these immunoregulatory effects of tobacco exposure. In this setting, in genetically predisposed subjects with a smoking related decreased ability to clear apoptotic cells, the excess levels of exposed intracellular antigens might lead to a breakdown in tolerance and production of autoantibodies, such as those to dsDNA. ${ }^{24} 27$

Freemer et al hypothesise that the association between dsDNA and smoking is explained by the formation of DNA adducts with resultant autoantibodies to the damaged DNA. In support of the DNA adduct hypothesis, they cite their observation that the positive association is only present in current smokers and not former smokers. Importantly, antibodies to DNA adducts have been shown to persist after smoking cessation, ${ }^{28}$ but the authors note that they have a half life of only 9-13 weeks. This hypothesis is plausible, but to date, there is no direct evidence that antibodies against DNA adducts are related to autoantibodies to dsDNA. Furthermore, in the multivariate analysis, the authors found non-significant associations between other ANA and exposure to tobacco, indicating that DNA adducts may not be the mechanism for all autoantibody formation in SLE. In addition, while autoantibodies to dsDNA are directly involved in lupus nephritis, they are not responsible for all the clinical manifestations of SLE and therefore do not fully explain the association between smoking and SLE.

\section{SUMMARY}

The findings of Freemer et al point to an important area of investigation in the pathogenesis of SLE. Exposure to tobacco has consistently been associated with RA and other autoimmune diseases. Therefore, studies are warranted to further define its relationship with SLE related autoantibodies as well as disease development and clinical course. Investigations aimed at identifying associations with specific organ involvement and disease severity in SLE are indicated. Likewise, studies examining the association between exposure to tobacco and other ANA would help to define further the relationship between smoking and SLE. The concept of a geneenvironment interaction is suggested by this study and should be pursued. Certainly, if the association between dsDNA and smoking is due to the formation of DNA adducts, evaluation for GST polymorphism may show that the association between dsDNA and smoking is increased in subjects with SLE who are GSTMI null..$^{29}$ Furthermore, studies demonstrating an association between smoking and ANA in subjects without lupus would have the added benefit of demonstrating an association between smoking and autoantibodies to dsDNA which is independent of disease activity. Mechanistic studies in animals would also help to clarify this area.

Finally, smoking is a common habit that is potentially modifiable. Because autoantibodies to dsDNA may affect disease course in SLE, smokers with SLE should be counselled to stop smoking. This is perhaps the most clinically relevant point to be gained from this article.

\section{ACKNOWLEDGEMENTS}

These studies were supported by K12 RR017707 and the Smyth Professorship in Rheumatology.

Ann Rheum Dis 2006;65:561-563.

doi: 10.1136/ard.2005.046052

\section{Authors' affiliations}

D S Majka, Division of Rheumatology, Northwestern University, Feinberg School of Medicine, Chicago, IL, USA

V M Holers, Division of Rheumatology, University of Colorado at Denver and Health Sciences Center, Denver, CO, USA

Correspondence to: Dr D S Majka, Northwestern University Feinberg School of Medicine, Division of Rheumatology, McGaw Pavilion, 240 East Huron St, \#2300, Chicago, IL 6061 1, USA; d-majka@northwestern.edu

Accepted 19 January 2006

Competing Interests: None

\section{REFERENCES}

1 Freemer MM, King TE Jr, Criswell LA. Association of smoking with dsDNA autoantibody production in systemic lupus erythematosus. Ann Rheum Dis 2006:65:581-4.
2 Heliovaara M, Aho K, Aromaa A, Knekt P, Reunanen A. Smoking and risk of rheumatoid arthritis. J Rheumatol 1993:20:1830-5.

3 Stolt P, Bengtsson C, Nordmark B, Lindblad S, Lundberg I, Klareskog $L$, et al. Quantification of the influence of cigarette smoking on rheumatoid arthritis: results from a population based casecontrol study, using incident cases. Ann Rheum Dis 2003;62:835-41

4 Padyukov L, Silva C, Stolt P, Alfredsson L, Klareskog L. A gene-environment interaction between smoking and shared epitope genes in HLA-DR provides a high risk of seropositive rheumatoid arthritis. Arthritis Rheum 2004;50:3085-92.

5 Klareskog L, Stolt $\mathrm{P}$, Lundberg K, Kallberg $\mathrm{H}$, Bengtsson C, Grunewald J, et al. A new model for an etiology of rheumatoid arthritis: smoking may trigger HLA-DR (shared epitope)-restricted immune reactions to autoantigens modified by citrullination. Arthritis Rheum 2006;54:38-46.

6 Mattey DL, Dawes PT, Fisher J, Brownfield A, Thomson W, Hajeer ÁH, et al. Nodular disease in rheumatoid arthritis: association with cigarette smoking and HLA-DRB1/TNF gene interaction. $J$ Rheumatol 2002;29:2313-18.

7 Saag KG, Cerhan JR, Kolluri S, Ohashi K, Hunninghake GW, Schwartz DA. Cigarette smoking and rheumatoid arthritis severity. Ann Rheum Dis 1997;56:463-9.

8 Wolfe $\mathbf{F}$. The effect of smoking on clinical, laboratory, and radiographic status in rheumatoid arthritis. J Rheumatol 2000;27:630-7.

9 Criswell LA, Merlino LA, Cerhan JR, Mikuls TR, Mudano AS, Burma M, et al. Cigarette smoking and the risk of rheumatoid arthritis among postmenopausal women: results from the lowa Women's Health Study. Am J Med 2002;112:465-71.

10 Karlson EW, Lee IM, Cook NR, Manson JE, Buring JE, Hennekens $\mathrm{CH}$. A retrospective cohort study of cigarette smoking and risk of rheumatoid arthritis in female health professionals. Arthritis Rheum 1999;42:910-17.

11 Jonsson T, Thorsteinsson J, Valdimarsson H. Does smoking stimulate rheumatoid factor production in non-rheumatic individuals? APMIS 1998; 106:970-4.

12 Mathews JD, Whittingham S, Hooper BM, Mackay IR, Stenhouse NS. Association of autoantibodies with smoking, cardiovascular morbidity, and death in the Busselton population. Lancet 1973;2:754-8.

13 Tuomi T, Heliovaara M, Palosuo T, Aho K. Smoking, lung function, and rheumatoid factors. Ann Rheum Dis 1990;49:753-6.

14 McDonagh JE, Walker DJ. Smoking and rheumatoid arthritis - observations from a multicase family study: comment on the article by Silman et al. Arthritis Rheum 1997;40:594.

15 Costenbader KH, Kim DJ, Peerzada J, Lockman S, Nobles-Knight D, Petri M, et al. Cigarette smoking and the risk of systemic lupus erythematosus: a meta-analysis. Arthritis Rheum 2004;50:849-57.

16 Ghaussy NO, Sibbitt WL Jr, Qualls CR. Cigarette smoking, alcohol consumption, and the risk of systemic lupus erythematosus: a case-control study. J Rheumatol $2001 ; 28: 2449-53$

17 Formica MK, Palmer JR, Rosenberg L, McAlindon TE. Smoking, alcohol consumption, and risk of systemic lupus erythematosus in the Black Women's Health Study. J Rheumatol 2003;30:1222-6.

18 Sanchez-Guerrero J, Karlson EW, Colditz GA, Hunter DJ, Speizer FE, Liang MH. Hair dye use and the risk of developing systemic lupus erythematosus. Arthritis Rheum 1996;39:657-62

19 Ward MM, Studenski S. Clinical prognostic factors in lupus nephritis. The importance of hypertension and smoking. Arch Intern Med 1992; 152:2082-8.

20 Ghaussy NO, Sibbitt W Jr, Bankhurst AD Qualls CR. Cigarette smoking and disease activity in systemic lupus erythematosus. I Rheumatol 2003;30:1215-21

21 Ho KT, Ahn CW, Alarcon GS, Baethge BA, Tan FK, Roseman J, et al. Systemic lupus erythematosus in a multiethnic cohort (LUMINA): 
XXVIII. Factors predictive of thrombotic events. Rheumatology (Oxford) 2005:44:1303-7.

22 Rubin RL, Hermanson TM, Bedrick EJ, McDonald JD, Burchiel SW, Reed MD, et al. Effect of cigarette smoke on autoimmunity in murine and human systemic lupus erythematosus. Toxicol Sci 2005;87:86-96.

23 Mattey DL, Hutchinson D, Dawes PT, Nixon NB, Clarke S, Fisher J, et al. Smoking and disease severity in rheumatoid arthritis: association with polymorphism at the glutathione S-transferase $M 1$ locus. Arthritis Rheum 2002:46:640-6.

24 Bijl M, Horst G, Limburg PC, Kallenberg CG. Effects of smoking on activation markers, Fas expression and apoptosis of peripheral blood lymphocytes. Eur J Clin Invest 2001;31:550-3.

25 Manderson AP, Botto $M$, Walport MJ. The role of complement in the development of systemic lupus erythematosus. Annu Rev Immunol 2004;22:431-56.

26 Kirkham PA, Spooner G, Rahman I, Rossi AG Macrophage phagocytosis of apoptotic neutrophils is compromised by matrix proteins modified by cigarette smoke and lipid peroxidation products. Biochem Biophys Res Commun 2004:318:32-7.

27 Bijl M, Limburg PC, Kallenberg CG. Smoking and increased apoptosis in patients with systemic lupus erythematosus: comment on the article by Costenbader et al. Arthritis Rheum 2004;50:3733.

28 Pulera N, Petruzzelli S, Celi A, Puntoni R, Fornai E, Sawe U, et al. Presence and persistence of serum anti-benzo[a]pyrene diolepoxide-DNA adduct antibodies in smokers: effects of smoking reduction and cessation. Int J Cancer 1997;70:145-9.

29 Zhao C, Vodicka P, Sram RJ, Hemminki K. DNA adducts of 1,3-butadiene in humans: relationships to exposure, GST genotypes, singlestrand breaks, and cytogenetic end points. Environ Mol Mutagen 2001 ;37:226-30.

\section{bmjupdates+}

bmjupdates+ is a unique and free alerting service, designed to keep you up to date with the medical literature that is truly important to your practice.

bmjupdates+ will alert you to important new research and will provide you with the best new evidence concerning important advances in health care, tailored to your medical interests and time demands.

Where does the information come from?

bmjupdates+ applies an expert critical appraisal filter to over 100 top medical journals A panel of over 2000 physicians find the few 'must read' studies for each area of clinical interest

Sign up to receive your tailored email alerts, searching access and more...

www.bmjupdates.com 